nection between the two phenomena probable. I have observed myself an extremely curious case in this respect on April 18,1842 ; at 9 . 10 A.M., I saw by chance that the needle of the declination instrument received a sudden jerk so that the scale was pushed out of the field of view of the telescope. The oscillations continued for some time; at last the ordinary tranquillity was restored. After some days I received the news from Colla, in Parma, that he had observed violent oscillations of the needle, and comparisons showed that the movement had begun at the same moment in Parma as in Munich. A short time after, the report of a French engineer was published, on a violent earthquake which be had observed in Greece ; and now it was found that the earthquake bad taken place in the same minute in which the oscillations of the needle had been observed in Parma and Munich. This, together with the many cases collected by Kreil and Colla, leaves scarcely any doubt as to the presence of a close connection; but it is undecided whether one phenomenon is the consequence of the other, or whether they both come from the same source. The same connection between earthquakes and magnetic disturbances was observed by Lamont at the earthquake which took place in Greece in December 1861. He communicates his observations to Poggendorff's Annalen (vol. cxy. $176)$ in the following words: "As the connection of the magnetism of the earth with earthquakes still belongs to the insufficiently ascertained relatives, it will not appear irrelevant if I communicate a fact bearing upon this question. On December 26 , I 861 , at 8 o'clock A.M., when I took down the position of the magnetical instruments (some of which are put up in the magnetical observatory, viz. two for declination, two for intensity, and two for dip), I observed in all the instruments an uncommon restlessness, consisting in a quick and irregular decrease and increase in the declination, and at the same time a trembling in the vertical direction. The trembling of the needle only lasted for a short time, but the quick changes lasted until $8.300^{\prime}$ clock with gradually increasing violence. Some days later the news was received of an earthquake which, exactly coincident with the above observations, had caused great destruction in many parts of (ireece." (Philosophical Magazine, June 1872.) This goes far to show that terrestrial magnetism it to be correlated with the force which is shrinking the earth. HeNRY H. HOWOR'TH

\section{COLLIERY EXPLOSIONS}

$\mathrm{I} T$ is astonishing that, notwithstanding the many gene1 rations during which coal-mining has been carried on in this country, so comparatively little has been done to investigate scientifically the causes of explosions in coal-mines, and thereby discover an antidote to a constantly recurring danger, one which adds considerably to the yearly bills of mortality, and still more to the number of widows and orphans. No doubt a considerable proportion of these sad accidents is owing to the carelessness of miners themselves, but very many are, without doubt, also due to ignorance, on the part of all concerned, of the conditions under which coal-mining must be carried on. Only the other day a melancholy tale of death and widespread mourning comes from Wigan-fifteen men killed, leaving belind them at least thirty-one persons destitute of the means of gaining a livelihood. We are afraid that the frequency of such accidents has made the public somewhat callous in the matter; but a little consideration must show the vast importance of acquiring a thorough knowledge of the conditions under which they may happen. To this end the parer recently read before the Royal Society by Mr. William Galloway, Inspector of Mines, is an important contribution; and we hope that the author and others who are competent will continue their investigations until, if explosions cannot be prevented, they may at least be foreseen and provided against.

The opinions promulgated by Sir Humphry Davy and the eminent Colliery Viewers who were his contemporaries, regarding the security afforded by the use of the safety-lamp, have been accepted with hesitation by many of their successors during the last twenty or thirty years and this is not to be wondered at when we consider the large number of disastrous explosions by which thousands of lives have been lost in mines in which these lamps were in constant use. The illustrious inventor himself had discovered and pointed out, that if the lamp were exposed to the action of an explosive current, the flame might pass through the meshes of the wire-gauze and so originate an explosion; but when in good order it was considered to be safe under all other circumstances, until the experiments were made which form the subject of $\mathrm{Mr}$. Galloway's paper.

At first, and for many years after the introduction of the safety-lamp, the cause of nearly every explosion was attributed to carelessness on the part of the workmen using it ; then it was observed that a quantity of firedamp, sufficient to render some of the air-currents explosive, was sometimes suddenly given off by the strata, and these " outbursts of gas," as they are called, were assumed in the absence of any other explanation, to have caused many explosions. On Dec. I2, 1866, however, the great explosion took place at the Oaks Colliery; as it was known to have happened simultaneously with the firing of a heavily-charged shot in pure air attention was drawn to the coincidence; and it appears that some search has usually been made for evidence of recent shot-firing in mines in which explosions have occurred since that date. Accordingly we find from the reports of the Inspectors of Mines that shot-firing was carried on in seventeen out of twenty-two collieries, at which important explosions have happened since Dec. 12, 1866; safety-lamps were certainly used in twelve of these collieries, and probably in the whole seventeen; in eight cases it was ascertained that a shot had blown out the tamping at or about the time of the explosion; in two an empty shot-hole was found from which it was supposed the tamping had been blown; in three a shot had been fired, bringing down the coal or rock; lastly, there were five collieries at which two or more explosions took place simultaneously, in different parts of the mine unconnected by a train of explosive gas. The Seaham explosicn was a remarkable one ; a heavily charged shot was fired in pure air in one of the in-take air-courses, and, according to the statement of three men who survived, the explosion of firedamp followed the shot immediately.

Two methods of accounting for the simultaneousness of the explosion of firedamp with the firing of the shot have been suggested in the reports of the Inspectors of Mines : one of them supposes that the firedamp has been ignited directly by the shot; the other that the concussion of the air caused by the explosion of gunpowder dislodges gas from cavities in the roof and from grooves, and that this gas passing along in the air-cur. rents is ignited at the lamps of the workmen. In some instances when it has been known to be highly improbable that any gas existed nearer to the shot-hole than Io, 20 , or even $40 \mathrm{ft}$., the advocates of the former hypothesis have taken it for granted that the gases issuing from the shot-hole were projected through the air as far as the accumulation of firedamp, retaining a sufficiently high temperature to ignite it on their arrival. On the other hand the advocates of the latter hypothesis have not attempted to show how the gas, which they assumed could be dislodged in quantity by a sound-wave and its reflections, could be ignited in those cases in which safetylamps only were used. It is no doubt highly probable, however, that when once an explosion of firedamp has been initiated in one way or another, and large bodies of air are driven through the passages of a mine with great velocity, explosive accumulations will be dislodged from cavities and grooves and pressed through the safety-lamps with the velocity requisite to pass the flame.

In the beginning of the year $1872 \mathrm{Mr}$. Galloway first thought it probable that a sound-wave originated by a blown-out shot, in passing through a safety-lamp burning in an explosive mixture, would carry the flame through 
the meshes of the wire-gauze in virtue of the vibration of the molecules of the explosive gas. An explosion which took place at Cethin Colliery in 1865 is a good example of one that may have been caused in this way. Several days after the explosion the safety-lamp of the overman was found securely locked and uninjured, lying at a distance of a few yards within an abandoned stall which was known to have contained firedamp. Shot-firing was carried on in this mine, and it is not improbable that a soundwave from an overcharged or blown-out shot had passed through this lamp and ignited the explosive mixture shortly after the overman had entered it ; moreover, the Inspector of Mines in his report says he has no doubt that the gas in this state was ignited and was therefore the origin of the expiosion, but he is unable to state by what means it was fired.

A number of experiments were made by $\mathrm{Mr}$. Galloway in connection with this subject ; the cost of apparatus, \&c., was provided for by the liberality of the Government Grant Committee of the Royal Society.

The first experiment was made on Jan. 16,1872 , in the physical laboratory of University College, London. A sheet of wire-gauze $\mathrm{r} \mathrm{ft}$. square was inclined at an angle of $70^{\circ}$ and a slow current of gas and air from a Bunsenburner was directed against its lower surface; part of the explosive mixture passed through the meshes, and when ignited produced a flat flame 3 in. long by $I$ in. wide about the middle of the upper surface of the wire-gauze. A glass tube $3 \mathrm{ft}$. $4 \mathrm{in}$. long by about $3 \frac{1}{2} \mathrm{in}$. diameter was placed horizontally with one end opposite to the flame on the same side of the wire-gauze and distant from it about $I \frac{1}{2}$ in. At the other end of this tube a sound-wave was produced by the explosion of a mixture of coal-gas and oxygen contained in soap-bubbles. When the soundwave passed through the tube the flame was carried through the meshes of the wire-gauze and ignited the gas issuing from the Bunsen-burner on the other side.

Some experiments similar to the first were made in one of the laboratories of the Royal College of Chemistry in Dec. I872. The glass tube was replaced by a tin-plate tube about $20 \mathrm{ft}$. long by $2 \mathrm{in}$. diameter: paper and other diaphragms were inserted at a distance of roft. from the origin of disturbance to insure that only a sound-wave was propagated through the tube. The results were the same as before.

Two sets of apparatus, a larger and a smaller, were then constructed; in both the sound-wave of a pistol-shot is conveyed through tin-plate tubes to a distance of about $20 \mathrm{ft}$., then it passes through a safety-lamp burning in an explosive mixture. In the smaller apparatus the tube is 3 in. in diameter; one end is closed by a disc of wood with a hole in the middle large enough to receive the muzzle of a pistol; at a distance of $10 \mathrm{ft}$. from the disc there is a diaphragm of sheet india-rubber, and at the farther end is a safesy-lamp with gas-flame. At the bottom of the safety-lamp there is a circular chamber with holes round about from which gas can be made to escape, and when this gas, rising up, mixes with the air it forms an explosive mixture surrounding the wire-gauze cylinder. The pistol by means of which the sound-wave is produced is charged with 205 gramme of gunpowder, and a tamping paper is rammed down well upon the charge. When the shot is fired through the hole in the wooden disc, while the explosive mixture surrounds the lighted safety-lamp, the flame is instantly carried through the meshes by the vibration, and ignites the gas on the outside. In the larger apparatus the tube is $8 \mathrm{in}$. in diameter, and $21 \mathrm{ft}$. long; at one end there is a wooden disc as before; at $20 \mathrm{ft}$. from the disc there is a sheet indiarubber diaphragm, and the extreme end is closed by a sheet of thin paper tied over it. Part of the last 12 in. (thus isolated from the rest of the tube and from the exterior) is enlarged sufficiently to hold a safety-lamp, and it is provided with an inlet below for air or air and gas, and a chimney above for the sake of the products of combustion. A lighted Davy or Clanny lamp of ordinary construction having been placed in this space, gas is made to mix with the air which flows up through it in consequence of the draught caused by the lamp: the appearances presented by the flame are observed through a small glass window, and when they indicate that the air is explosive the shot is fired. The flame within the safetylamp is passed through the meshes, explodes the mixture in the isolated space, blowing out the paper end, and, passing backwards through the inlet, ignites the gas where it first mixes with air. In this case the shot consists of 4I gramme of gunpowder tamped as before.

The lamps that were tested in this apparatus are those known as the Davy, Clanny, Stephenson, Mueseler, and Eloin. The flame was easily passed through the Davy lamp, with rather more difficulty through the Clanny, and not at all through any of the others.

The first experiments with these two sets of apparatus were made in January and February 1873 , at the Meteorological Office, where Mr. Scott most kindly provided accommodation: the experiment with the smaller apparatus was shown at the Royal Institution, by Mr. Spottiswoode, on the evening of Jan. 17 ; and afterwards at one of the Cantor Lectures of the Society of Arts, by the Rev. Arthur Rigg. The next experiments were made in No. 7 Pit, Barleith, near Glasgow, with firedamp from a blower, but the flame could not be passed through the safety-lamps on account of the impurity of the gas, which contained only $75^{.86}$ of light carburetted hydrogen. The last experiments were made in the $\mathrm{C}$ Pit of Hebburn Col. liery, near Newcastle-on-Tyne, also with firedamp from a blower, and as the firedamp was very explosive, the flame was easily passed through the Davy-lamps of each apparatus.

After this, experiments were made on a larger scale in part of a new sewer in North Woodside Road, Glasgow. The sewer is ovoid in section; it is $6 \mathrm{ft}$. high and $4 \mathrm{ft}$. wide at its greatest dimensions; part of it is a tunnel in the solid rock, part is built in brickwork through surface drift. The gas safety-lamp of the smaller apparatus was placed on a board fixed across the sewer at a height of $2 \mathrm{ft} .8 \mathrm{in}$. from the bottom, and surrounded with an explosive mixture of coal-gas and air in the same way as when it was used in connection with the tin-plate tubes. Shots were fired from a pistol at certain distances from the lamp (the details of the distances and the charges required to pass the flame in the paper and sections of the sewer are given in the plates which accompany it). One hundred and nine feet was the greatest distance available in the part built of brick, and at this point a sound-wave of sufficient intensity to pass the flame was produced by firing a charge of 3.882 grammes $=59$ grains of gunpowder. At $96 \mathrm{ft}$. from the lamp a charge of 3.276 grammes was required when the sound-wave passed through the brickwork tunnel all the way, and 2.184 grammes when it passed through the tunnel in the solid rock. These experiments seem to be perfectly conclusive.

Mr. Galloway's discovery - that when the vibration of the air which constitutes a sound-wave has a certain amplitude, it can transmit flame through the wire-gauze of the Davy and Clanny lamps-furnishes an additional argument against retaining these lamps in use, at least in the hands of ordinary workmen. On Dec. 15 , 1815, Davy said he was convinced that, as far as ventilation was concerned, the resources of modern science had been fully employed; he then proceeded to describe a "safety lantern," which is identical in principle with the Stephenson lamp, and is extinguished in an explosive mixture (Phil. Trans. I8I6, p. 2). This "safety lantern" was afterwards discarded in favour of the Davy lamp proper, the principal advantage of which was stated to be that it would not only preserve the col- 
lier from the firedamp, but enable him to apply it to use, and destroy it at the same time that it gave him a useful light (Phil. Trans. I816, pp. 23 and 24). Fortunately the ventilation of mines is now better understood than it was in the days of Davy, and the quantities of air employed are usually very much greater. It is certain, however, that in some mines of the present day the ventilation could be doubled or trebled with advantage; and since this is merely a matter of expense it may be asked why it is not done, when it would ensure comparative immunity from danger? On the other hand it is now almost universally admitted to be highly dangerous to continue work in an explosive atmosphere, so that safety-lamps should be used only as a precaution against possible outbursts of gas or when work is carried on in the neighbourhood of gas that cannot be easily dislodged; it is evident, therefore, primâ facie, that lamps constructed on the principle of the "safety-lantern," such as the Stephenson, Mueseler, \&c., which are extinguished in an explosive mixture, are far safer than lamps like the Davy or Clanny, which continue to burn under the same circumstances, and are then liable, at any instant, to have the flame driven through the wire gauze and communicated to the external explosive atmosphere.

\section{THE COMET}

[The following letter appeared in last Thursday's Times, from the columns of which journal it is reproduced, with a few verbal alterations.]

I WAS enabled on Sunday night (12th inst.), by Mr. Newall's kindness, to spend several hours in examining the beautiful comet which is now visiting us, by means of his monster telescope--a refractor of $25 \mathrm{in}$. aperture, which may safely be pronounced the finest telescope in the world, or, at all events, in the Old World.

The view of the comet which I obtained utterly exceeded my expectations, although I confess they were by no means moderate; and as some of the points suggested by the observations are, I think, new, and throw light upon many recorded facts, I beg a small portion of space in the Times to refer to them, as it is important that observers should have their attention called to them before the comet leaves us.

I will first deal with the telescopic view of the comet. Perhaps I can give the best idea of the appearance of the bright head in Mr. Newall's telescope, with a low power, by asking the reader to imagine a lady's fan opened out $\left(160^{\circ}\right)$ until each side is almost a prolongation of the other. An object resembling this is the first thing that strikes the eye, and the nucleus, marvellously small and definite, is situated a little to the left of the pin of the fan-not exactly, that is, at the point held in the hand. The nucleus is, of course, brighter than the fan.

Now, if this comet, outside the circular outline of the fan, offered indications of other similar concentric circular outlines, astronomers would have recognised in it a great similarity to Donati's beautiful comet of 1858 with its "concentric envelopes." But it does not do so. The envelopes are there undoubtedly, but, instead of being concentric, they are excentric, and this is the point to which I am anxious to draw attention, and, at the risk of being tedious, I must endeavour to give an idea of the appearance presented by these excentric envelopes. Still referring to the fan, imagine a circle to be struck from the left-hand corner with the right-hand corner as a centre, and make the arc a little longer than the arc of the fan. Do the same with the right-hand corner. Then with a gentle curve connect the end of each arc with a point in the arc of the fan half-way between the centre and the nearest corner. If these complicated operations have been properly performed the reader will have superadded to the fan two ear-like things, one on each side. Such "ears," as we may for convenience call them, are to be observed in the comet, and they at times are but little dimmer than the fan.

At first it looked as if these ears were the parts of the head furthest from the nucleus along the comet's axis, but careful scrutiny revealed, still in advance, a cloudy mass, the outer surface of which was regularly curved, convex side outwards, while the contour of the inner surface exactly fitted the outer outline of the ears and the intervening depression. This mass is at times so faint as to be invisible, but at other times it is brighter than all the other details of the comet which remain to be described, now that I have sketched the groundwork. These details consist of prolongations of all the curves I have referred to backwards into the tail.

Thus, behind the bright nucleus is a region of darkness (a black fan with its pin near the pin of the other pendant from it, and opened out $45^{\circ}$ or $60^{\circ}$ only will represent this), the left-hand boundary of which is a continuation of the lower curve of the right ear. The righthand boundary is similarly a continuation of the lower curve of the left ear. Indeed, I may say generally-not to enter into too minute description in this place-that all the boundaries of the several different shells which show themselves, not in the head in front of the fan, but in the root of the tail behind the nucleus, are continuous in this way-the boundary of an interior shell on one side of the axis bends over in the head to form the boundary of an exterior shell on the other side of the axis.

At last, then, I have finished my poor and, I fear, tiresome description of the magnificent and truly wonderful sight presented to me as it was observed, on the whole, during some hours' close scrutiny under exceptional atmospheric conditions.

I next draw attention to the kind of change observed. To speak in the most general terms, any great change in one "ear" was counterbalanced by a change of an opposite character in the other; so that when one ear thinned or elongated, the other widened; when one was dim, the other was bright; when one was more "pricked" than usual, the other at times appeared to lie more along the curve of the fan and to form part of it. Another kind of change was in the fan itself, especially in the regularity of its curved outline and in the manner in which the straight sides of it were obliterated altogether by light, as it were, streaming down into the tail.

The only constant feature in the comet was the exquisitely soft darkness of the region extending for some little distance behind the nucleus. Further behind, where the envelopes of the tail were less marked, the delicate veil which was over even the darkest portion became less delicate, and all the features were merged into a mere luminous haze. Here all structure, if it existed, was nonrecognisable, in striking contrast with the region round and immediately behind the fan.

Next it has to be borne in mind that the telescopic object is after all only a section, from which the true figure has to be built up, and it is when this is attempted that the unique character of this comet becomes apparent. There are no jets, there are no concentric envelopes; but, as I have said, in place of the latter, excentric envelopes indicated by the ears and their strange backward curvings, and possibly also by the fan itself.*

I prefer rather to lay the facts before observers than to state the conclusions to be derived from them, but I cannot help remarking that, supposing the comet to be a meteor-whirl, the greatest brilliancy is observable where the whirls cut or appeax to cut each other; where we should have the greatest number of particles, of whatever nature they may be, in the line of sight; and not only so,

* By describing three parabolas on a card and spinning the card rapidiy round a line not coincident with their common axis, I have been able to reproduce roughly the appearances figured last week and described above, -J.N.I. 